\title{
What does a good RCT recruitment consultation look like? A new simple six-step model to promote information sharing and recruitment to RCTs
}

\author{
Alba Realpe ${ }^{1 *}$, Ann Adams ${ }^{1}$, Peter Wall ${ }^{1}$, Damian Griffin ${ }^{1}$, Jenny L Donovan ${ }^{2}$ \\ From 3rd International Clinical Trials Methodology Conference \\ Glasgow, UK. 16-17 November 2015
}

\section{Objective}

The mode of delivery of trial information is a key determinant of recruitment to randomised controlled trials (RCTs), which can be modified in order to encourage patients to participate. This paper presents the development and initial validation of a simple six-step model to support recruitment.

\section{Study design and setting}

92 recruitment consultations with 60 new patients were recorded and analysed during a pilot RCT comparing surgical and non-surgical interventions for hip impingement. Recordings were analysed using techniques of thematic analysis and focused conversation analysis pioneered in previous studies. Analysis of recordings continued during the full-scale trial.

\section{Results}

The pilot study was successful, with $70 \%$ of patients approached across 9 centres agreeing to take part in the RCT, and the full-scale trial has achieved $75 \%$ recruitment in 19 centres. A simple six-step model providing a framework for good recruitment practice was developed at the pilot phase and then validated, and tested in the main trial. . The model enabled recruiters to explain the design and conduct of the RCT and provide reassuring information for patients in the context of consultations very different from routine practice.

\section{Conclusion}

The six-step model provides a useful framework for recruitment to RCTs. It encourages the implementation

${ }^{1}$ University of Warwick, Coventry, UK

Full list of author information is available at the end of the article of good RCT recruitment practice and provides strategies to support recruiters. The model requires further testing in a wide range of RCTs and clinical contexts.

Authors' details

'University of Warwick, Coventry, UK. ${ }^{2}$ University of Bristol, Bristol, UK.

Published: 16 November 2015

doi:10.1186/1745-6215-16-S2-O21

Cite this article as: Realpe et al:: What does a good RCT recruitment

consultation look like? A new simple six-step model to promote

information sharing and recruitment to RCTs. Trials 2015 16(Suppl 2):O21.
Submit your next manuscript to BioMed Central and take full advantage of:

- Convenient online submission

- Thorough peer review

- No space constraints or color figure charges

- Immediate publication on acceptance

- Inclusion in PubMed, CAS, Scopus and Google Scholar

- Research which is freely available for redistribution
() Biomed Central 